\title{
Antioxidant activity of mangrove-derived marine thraustochytrids
}

\author{
Kalidasan K, Sunil KS, Narendran R and Kathiresan K \\ Centre of Advanced Study in Marine Biology, Faculty of Marine Sciences, Annamalai University, \\ Parangipettai: 608 502, Tamil Nadu, India
}

Kalidasan K, Sunil KS, Narendran R and Kathiresan K 2015 - Antioxidant activity of mangrovederived marine thraustochytrids. Mycosphere 6(5), 602-611, Doi 10.5943/mycosphere/6/5/9

\begin{abstract}
Antioxidants are compounds that inhibit the reaction caused by free radicals thereby preventing or delaying damage to the cells and tissues. Protection against free radicals can be enhanced by taking sufficient amounts of exogenous antioxidants. The present study evaluated the antioxidant activity of the mangrove-derived thraustochytrids for their potential health benefits. Thirteen thraustochytrid strains were isolated from mangrove leaf litter, extracted them separately in methanol and tested for their antioxidant activity by using six different assays: DPPH radical scavenging, total phenol content, hydrogen peroxide radical inhibition, nitric oxide radical assay and total reducing power activity. The antioxidant activity was found significant between the thraustochytrid strains and between concentrations of their extracts $(\mathrm{P}<0.05)$. The activity also increased with concentration of the extracts. The strain TSKK1 exhibited highest $(78.95 \pm 1.29)$ antioxidant activity and TSSK5 the lowest antioxidant activity (72.52 \pm 2.03$)$. This study proved the potent free radical scavenging and antioxidant activity of thraustochytrids.
\end{abstract}

Keywords - DPPH - free radicals - leaf litter - nitric oxide - total phenol

\section{Introduction}

Antioxidants play an important role to protect the human body against oxidative damage caused by free radicals. An antioxidant is a molecule, capable of inhibiting other molecular oxidation. Oxidative free radicals are highly reactive to attack molecules by capturing electrons and thus modifying chemical structures. Free radicals are harmful substances, produced during the normal metabolic process. The free radicals are generated through the oxidation of carbohydrates, fats and proteins through both aerobic and anaerobic processes. Over-production of the free radicals is responsible for tissue injury (Gomathi et al. 2013a). Cell membranes are made up of unsaturated lipids which are particularly susceptible to free radicals, which will breakdown or even harden the lipids of cell membrane. This interferes with the cells to get proper nutrients or intercellular signals and eventually leads to cell death (Khansari et al. 2009, Halliwell et al. 1987). In a normal healthy individual, there should be a well- maintained balance between free radical production and antioxidant defense mechanisms. However, in a diseased state, this balance shifts towards the overproduction of free radicals or deficit in antioxidant defense mechanisms and may lead to oxidative stress.

In the human body, there are various enzyme systems for free radical scavenging, but micronutrients such as vitamin $\mathrm{E}$, beta-carotene and vitamin $\mathrm{C}$ are the major antioxidants. These must be provided in diet as the body cannot produce these nutrients. Protection against free radicals 
can be enhanced by taking sufficient amounts of exogenous antioxidants (Halliwell 1995). Lipid oxidation is one of the major causes for deterioration of many food products. It leads to changes in texture, flavor, odor and quality of foods. The lipid oxidation also causes some health hazards in human beings such as cardiovascular disease, cancers and neurological disorders as well as aging process (Gulcin 2011, 2012). Highly reactive free radicals and oxygen species are present in biological systems from a wide variety of sources. These free radicals may oxidize nucleic acids, proteins, lipid or DNA and can initiate degenerative diseases. Reactive radicals play a very important role in signal transduction (Lee et al. 2004). However, excess free radicals can give rise to some diseases. Lipid peroxidation during processing and storage of foods can cause unacceptable flavor and taste, decrease consumer acceptability for foods. Numerous numbers of both natural and synthetic antioxidants are suggested for various human diseases (Cuzzocrea 2001). Some manmade antioxidant compounds such as butylated hydroxytoluene, butylated hydroxyanisole and tertiary butylhydroquinone are commonly used in processed foods. However, synthetic antioxidants have shown potential health risks and toxicity, most notably possible carcinogenicity. Therefore, it is of great importance to find new sources of safe and inexpensive antioxidants of natural origin in order to use them in foods and pharmaceutical preparations to replace synthetic antioxidants (Lee et al. 2004, Song 2010).

Mangrove-derived fungi and fungal-like organisms have been recognized as a repository of novel secondary metabolites, some of which have beneficial biological activities and recently numerous novel bioactive substances have been isolated from these microorganisms (Wagenaar \& Clardy 2001, Brady et al. 2001, Shrestha et al. 2001, Kongsaeree et al. 2003, Sridhar 2004, Kathiresan \& Qasim 2005, Kim 2013, Saravanakumar \& Kathiresan 2014). There are however, only limited studies on antioxidant potential of thraustochytrids. Therefore, in the present study the antioxidant activity of the mangrove-derived thraustochytrids was evaluated for their potential health benefits.

\section{Material and Methods}

\section{Microbial culture and extraction}

Pure strains of Thraustochytrids isolated from decaying mangrove leaf litter in our laboratory were used for the present study. Fresh cultures of 13 thraustochytrids (TSKK1, TSKK2, TSKK3, TSKK4, TSKK5, TSKK6, TSKK7, TSKK8, TSKK9, TSKK10, TSKK11, TSKK12 and TSKK13) were cultured separately in one ml of medium composed of ( $50 \%$ seawater) glucose $\left(10 \mathrm{~g} .1^{-1}\right)$, yeast $\left(10 \mathrm{~g} . \mathrm{l}^{-1}\right)$, peptone $\left(1 \mathrm{~g} . \mathrm{l}^{-1}\right)$, thiamine $\left(0.5 \mathrm{~g} . \mathrm{l}^{-1}\right)$ in $50 \%$ seawater, and then inoculated to $100 \mathrm{ml}$ of the medium, maintained at different $\mathrm{pH}$, temperature, salinity and source of carbon and nitrogen for 7 days (Gomathi 2009, 2011). Then biomass was air-dried and extracted in $80 \%$ methanol. The extract was filtered through Whatman No.1 filter paper, and the filtrate was evaporated to dryness under vacuum at $40^{\circ} \mathrm{C}$ (Gomathi et al. 2013b).

\section{Antioxidant assays}

Based on the antimicrobial activity in the crude extracts, five potent thraustochytrids(TSKK1, TSKK3, TSKK5, TSKK9 and TSKK11) were selected for the antioxidant activity (Data not shown). The antioxidant activity of the extracts, prepared in different concentrations 50, 100, 200, 250, $500 \mu \mathrm{g} \cdot \mathrm{ml}^{-1}$ was tested for antioxidant property by using standard assay methods: Determination of total phenol content (Singleton et al. 1999), DPPH radical scavenging assay (Duan et al. 2006), Total antioxidant activity (Prieto et al. 1999), Measurement of reducing power (Oyaizu 1986), Nitric oxide radical inhibition assay (Govindarajan et al. 2003, Badami et al. 2005) and Hydrogen peroxide radical inhibition assay (Govindarajan et al. 2003, Gulcin et al. 2004). Each experiment was done in triplicate and mean values were taken.

The scavenging activity was calculated by using the following formula and is expressed in per cent.

$\%$ activity $=[($ control absorbance $($ Ac) $)$ extract absorbance $($ As $) /($ control absorbance $($ Ac $))] \times 100$ Where $\mathrm{Ac}=$ control, and As $=$ sample 


\section{Statistical analysis}

Statistical analysis was performed by using the SPSS (version-16). All in vitro results were calculated as mean \pm SD and were analyzed by one-way analysis of ANOVA followed by Duncan's multiple range test. The $P$ values less than 0.05 were considered statistically significant.

\section{Results}

\section{Total antioxidant assay}

The total antioxidant activity was significant between five thraustochytrids (TSKK1, TSKK3, TSKK5, TSKK9 and TSKK11) and also between the concentrations of their extracts $(\mathrm{P}<0.05)$. The antioxidant activity increased with increasing concentrations of the extracts of thraustochytrids. The extract of the TSKK1 exhibited the highest (78.95 \pm 1.29$)$ antioxidant activity and TSSK5 showed the lowest activity (72.52 \pm 2.03 ) (Table 1, Fig.1).

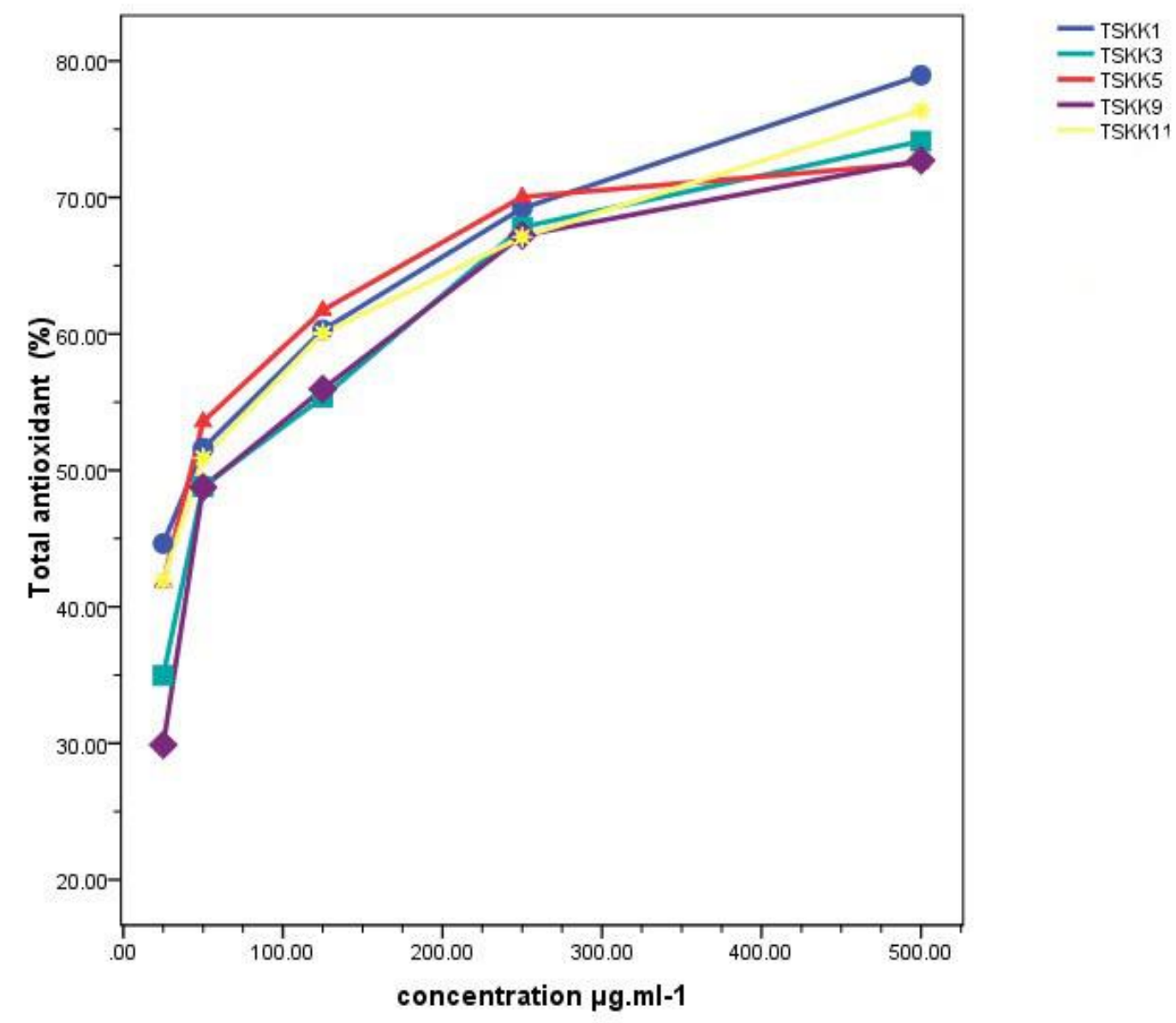

Fig. 1 - Total antioxidant (\%) activity in extracts of mangrove-derived thraustochytrids, at different concentrations.

\section{DPPH free-radicals scavenging assay}

The DPPH Free-radical scavenging assay was significant between thraustochytrids and also between the concentrations of their extracts $(\mathrm{P}<0.05)$ (Table 1). The decrease in absorbance of the radical was due to hydrogen donation. It was visually noticeable as the colour changed from purple to yellow. TSSK9 was found be the highest producer of free radical scavenging activity $(81.20 \pm 3.01)$ as compared to other thraustochytrids extracts. TSSK1 was found to be the lowest in free radical scavenging activity (71.15 \pm 1.90$)$ (Table 1, Fig.2). 
Table 1 Antioxidant activity in crude extracts of mangrove-derived thraustochytrids, at different concentrations.

\begin{tabular}{|c|c|c|c|c|c|c|}
\hline \multirow{2}{*}{$\begin{array}{l}\text { Scavenging } \\
\text { assay }\end{array}$} & \multirow{2}{*}{$\begin{array}{l}\text { Concentration } \\
\mu \mathrm{g} / \mathrm{ml}\end{array}$} & \multicolumn{5}{|c|}{ \% scavenging activity of different strains of thraustochytrids } \\
\hline & & TSKK1 & TSKK3 & TSKK5 & TSKK9 & TSKK11 \\
\hline \multirow{3}{*}{ Total phenol } & 25 & $39.20 \pm 0.83$ & $28.82 \pm 2.09$ & $41.77 \pm 1.36$ & $42.79 \pm 2.34$ & $31.86 \pm 1.46$ \\
\hline & 50 & $66.27 \pm 2.50$ & $37.56 \pm 1.87$ & $60.15 \pm 1.33$ & $51.81 \pm 1.75$ & $62.35 \pm 2.83$ \\
\hline & 125 & $75.41 \pm 2.00$ & $43.85 \pm 1.66$ & $63.04 \pm 2.60$ & $57.38 \pm 1.58$ & $69.64 \pm 0.80$ \\
\hline \multirow{6}{*}{$\begin{array}{c}\text { Total } \\
\text { antioxidant }\end{array}$} & 250 & $81.38 \pm 2.75$ & $58.43 \pm 2.91$ & $71.25 \pm 1.03$ & $65.59 \pm 2.92$ & $72.32 \pm 1.32$ \\
\hline & 500 & $87.15 \pm 2.25$ & $68.84 \pm 2.79$ & $76.54 \pm 1.39$ & $75.26 \pm 2.39$ & $80.20 \pm 1.49$ \\
\hline & 25 & $44.63 \pm 2.05$ & $34.96 \pm 1.86$ & $41.80 \pm 2.24$ & $29.88 \pm 1.81$ & $41.93 \pm 2.34$ \\
\hline & 50 & $51.62 \pm 2.41$ & $48.82 \pm 1.43$ & $53.57 \pm 2.96$ & $48.75 \pm 1.31$ & $50.90 \pm 2.35$ \\
\hline & 125 & $60.29 \pm 1.45$ & $55.35 \pm 2.05$ & $61.73 \pm 1.85$ & $55.95 \pm 2.46$ & $60.04 \pm 2.87$ \\
\hline & 250 & $69.20 \pm 1.62$ & $67.82 \pm 2.68$ & $70.03 \pm 1.65$ & $67.21 \pm 2.98$ & $67.10 \pm 2.81$ \\
\hline \multirow{5}{*}{$\begin{array}{l}\text { DPPH radical } \\
\text { scavenging } \\
\text { activity }\end{array}$} & 500 & $78.95 \pm 1.29$ & $74.12 \pm 2.15$ & $72.52 \pm 2.03$ & $72.71 \pm 2.23$ & $76.37 \pm 1.42$ \\
\hline & 25 & $29.10 \pm 2.65$ & $37.86 \pm 2.58$ & $35.98 \pm 2.77$ & $41.88 \pm 1.55$ & $28.63 \pm 3.24$ \\
\hline & 50 & $43.13 \pm 2.73$ & $46.52 \pm 2.87$ & $41.30 \pm 2.77$ & $51.26 \pm 2.37$ & $47.22 \pm 2.61$ \\
\hline & 125 & $58.03 \pm 1.95$ & $53.47 \pm 2.14$ & $52.18 \pm 2.26$ & $63.41 \pm 2.29$ & $57.83 \pm 2.19$ \\
\hline & 250 & $62.10 \pm 2.66$ & $66.01 \pm 2.88$ & $69.44 \pm 2.76$ & $73.21 \pm 2.43$ & $63.42 \pm 2.36$ \\
\hline \multirow{5}{*}{$\begin{array}{l}\text { NO radical } \\
\text { scavenging } \\
\text { activity }\end{array}$} & 500 & $71.15 \pm 1.90$ & $71.77 \pm 1.76$ & $78.10 \pm 2.78$ & $81.20 \pm 3.01$ & $79.09 \pm 2.43$ \\
\hline & 25 & $38.30 \pm 2.81$ & $43.46 \pm 2.70$ & $42.47 \pm 2.17$ & $31.46 \pm 1.51$ & $34.92 \pm 2.42$ \\
\hline & 50 & $47.79 \pm 2.32$ & $52.03 \pm 1.78$ & $51.22 \pm 2.63$ & $49.32 \pm 2.04$ & $48.14 \pm 2.51$ \\
\hline & 125 & $54.02 \pm 2.75$ & $60.37 \pm 1.97$ & $62.18 \pm 1.64$ & $57.01 \pm 1.65$ & $58.26 \pm 1.53$ \\
\hline & 250 & $64.96 \pm 2.51$ & $69.00 \pm 2.73$ & $68.50 \pm 1.46$ & $65.65 \pm 1.71$ & $62.49 \pm 1.82$ \\
\hline \multirow{4}{*}{$\begin{array}{c}\mathrm{H}_{2} \mathrm{O}_{2} \text { radical } \\
\text { scavenging } \\
\text { activity }\end{array}$} & 500 & $75.28 \pm 2.92$ & $72.90 \pm 2.47$ & $74.77 \pm 2.40$ & $71.33 \pm 2.89$ & $73.44 \pm 1.68$ \\
\hline & 25 & $33.79 \pm 2.06$ & $40.31 \pm 2.71$ & $31.22 \pm 2.96$ & $42.16 \pm 1.19$ & $36.20 \pm 2.46$ \\
\hline & 50 & $44.64 \pm 2.34$ & $52.97 \pm 1.73$ & $48.05 \pm 2.41$ & $52.53 \pm 2.02$ & $49.74 \pm 2.73$ \\
\hline & 125 & $49.48 \pm 2.63$ & $61.06 \pm 1.70$ & $55.38 \pm 2.43$ & $60.66 \pm 2.10$ & $57.68 \pm 2.30$ \\
\hline \multirow{7}{*}{$\begin{array}{c}\text { Total reducing } \\
\text { power }\end{array}$} & 250 & $63.17 \pm 2.50$ & $69.51 \pm 2.94$ & $66.79 \pm 2.32$ & $73.07 \pm 2.11$ & $64.90 \pm 2.29$ \\
\hline & 500 & $70.88 \pm 2.92$ & $75.30 \pm 1.84$ & $76.24 \pm 2.55$ & $81.27 \pm 2.49$ & $77.03 \pm 1.19$ \\
\hline & 25 & $37.22 \pm 1.93$ & $32.12 \pm 2.36$ & $31.11 \pm 1.75$ & $36.33 \pm 1.11$ & $40.81 \pm 2.42$ \\
\hline & 50 & $41.61 \pm 2.10$ & $44.78 \pm 2.86$ & $42.95 \pm 2.71$ & $42.94 \pm 2.50$ & $49.23 \pm 2.75$ \\
\hline & 125 & $51.420 \pm 0.7$ & $53.70 \pm 1.63$ & $57.43 \pm 0.96$ & $52.02 \pm 1.69$ & $51.90 \pm 2.42$ \\
\hline & 250 & $59.86 \pm 2.45$ & $61.08 \pm 1.31$ & $65.48 \pm 2.52$ & $63.47 \pm 2.12$ & $64.98 \pm 2.57$ \\
\hline & 500 & $70.23 \pm 2.72$ & $73.58 \pm 3.42$ & $73.07 \pm 2.16$ & $73.48 \pm 2.32$ & $78.43 \pm 2.81$ \\
\hline
\end{tabular}

Values between concentrations or strains significant at $0.05 \%$ level
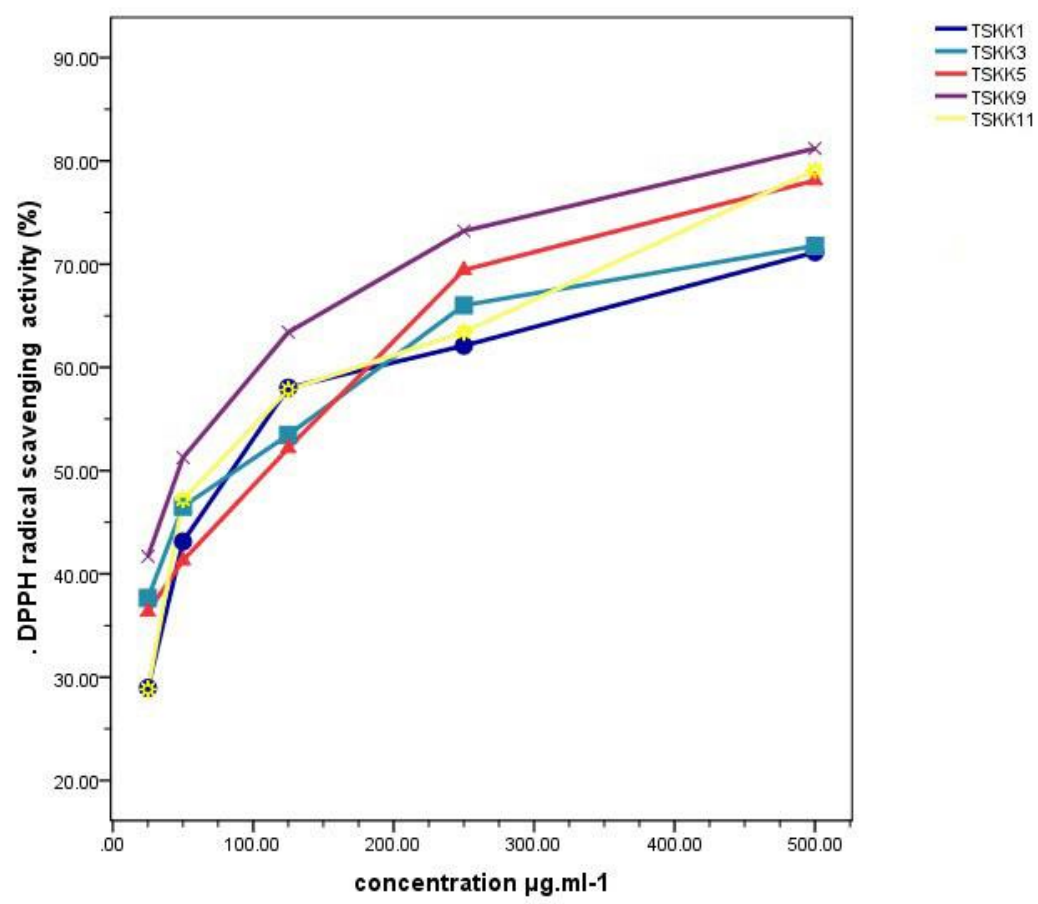

Fig. 2 - DPPH free-radicals scavenging (\%) activity in extracts of mangrove-derived thraustochytrids, at different concentrations. 


\section{Total phenol assay}

The total phenolic content was significant between five thraustochytrids (TSKK1, TSKK3, TSKK5, TSKK9 and TSKK11) and also between concentrations of their extracts $(\mathrm{P}<0.05)$ (Table 1). TSKK1 was found to be the highest in total phenol content $(87.15 \pm 2.25)$ and TSSK3 was found to be the lowest $(68.84 \pm 2.79)$ and TSKK11 (Table 1, Fig.3).

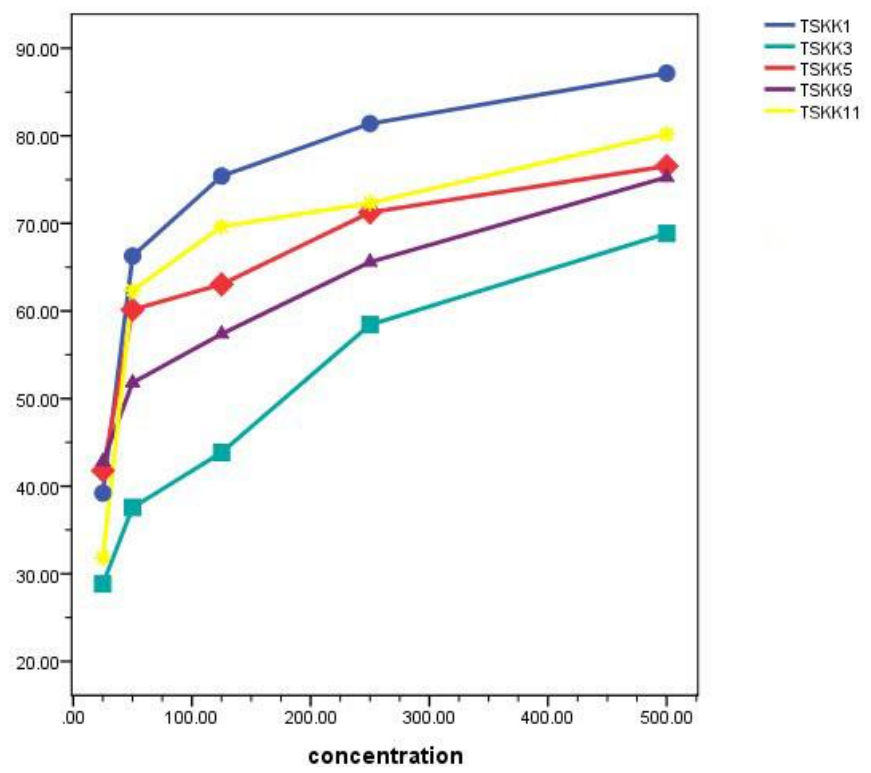

Fig. 3 - Total phenol (\%) content in extracts of mangrove-derived thraustochytrids, at different concentrations.

\section{Hydrogen peroxide radical inhibition assay}

The hydrogen peroxide radical inhibition activity was significant between five thraustochytrids (TSKK1, TSKK3, TSKK5, TSKK9 and TSKK11) and also between concentrations of their extracts $(\mathrm{P}<0.05)$ (Table.1). Hydrogen peroxide radical scavenging potential of TSKK9 was found to be $81.27 \pm 2.49 \mu \mathrm{g} / \mathrm{ml}$ and this value was higher than that of other extracts (TSKK1, TSKK3, TSKK5 and TSKK11), whereas the TSSK1 was found be lowest in radical scavenging activity (70.88 \pm 2.92$)$ (Table 1, Fig.4).

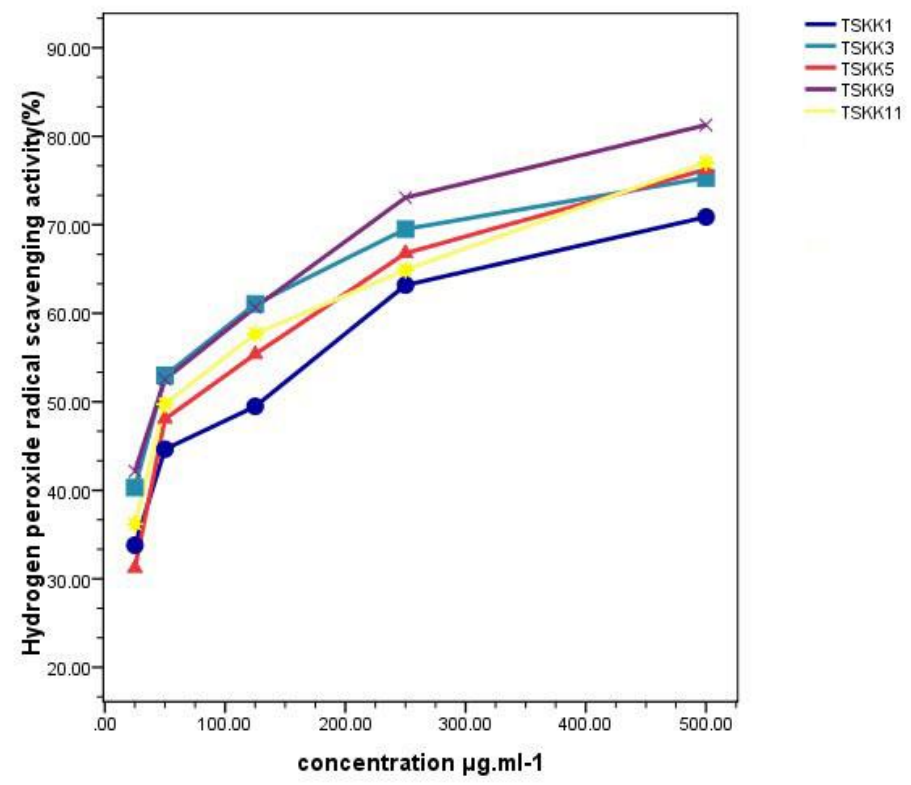

Fig. 4 - Hydrogen peroxide radical inhibition (\%) activity in extracts of mangrove-derived thraustochytrids, at different concentrations. 


\section{Nitric oxide radical inhibition assay}

The nitric oxide radical activity was significant between five thraustochytrids (TSKK1, TSKK3, TSKK5, TSKK9 and TSKK11) and also between concentrations of their extracts $(\mathrm{P}<0.05)$ (Table.1). TSKK1 was found be highest in nitric oxide radical content $(75.28 \pm 2.92)$ and TSKK9 was the lowest (71.33 \pm 2.89 ) (Table 1, Fig.5).
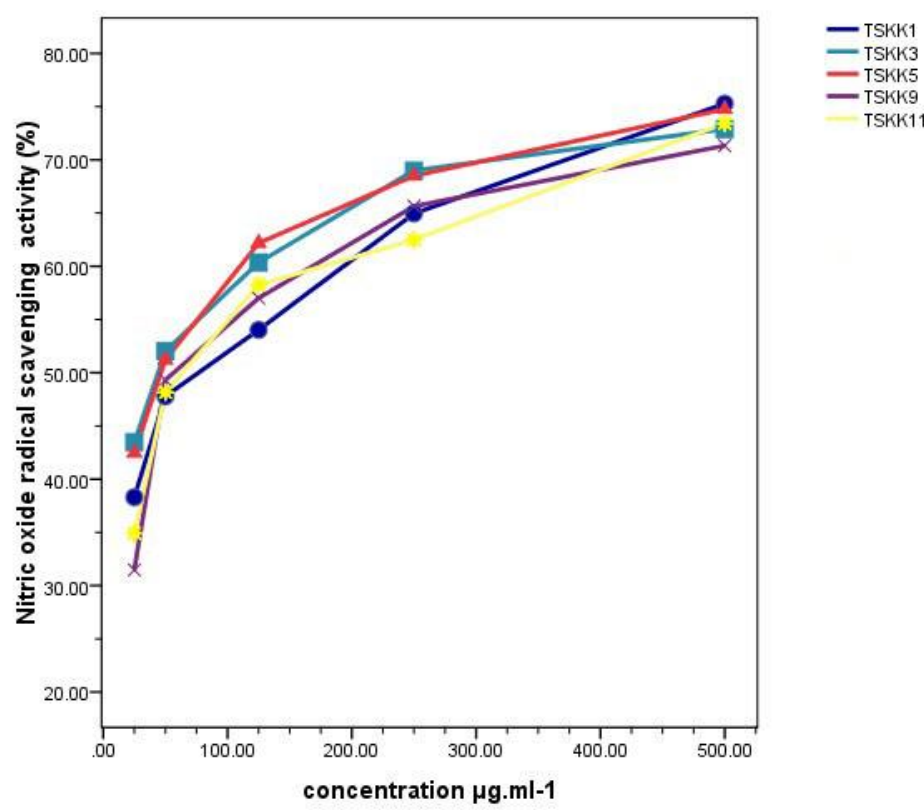

Fig. 5 - Nitric oxide radical inhibition (\%) activity in extracts of mangrove-derived thraustochytrids, at different concentrations.

\section{Total reducing power assay}

The total reducing power was significant between five thraustochytrids (TSKK1, TSKK3, TSKK5, TSKK9 and TSKK11) and also between concentrations of their extracts $(\mathrm{P}<0.05)$ (Table.1). TSKK11 was found be highest in total reducing power $(78.43 \pm 2.81)$ and TSKK9 was the lowest (70.23 \pm 2.72 ) (Table 1, Fig.6).
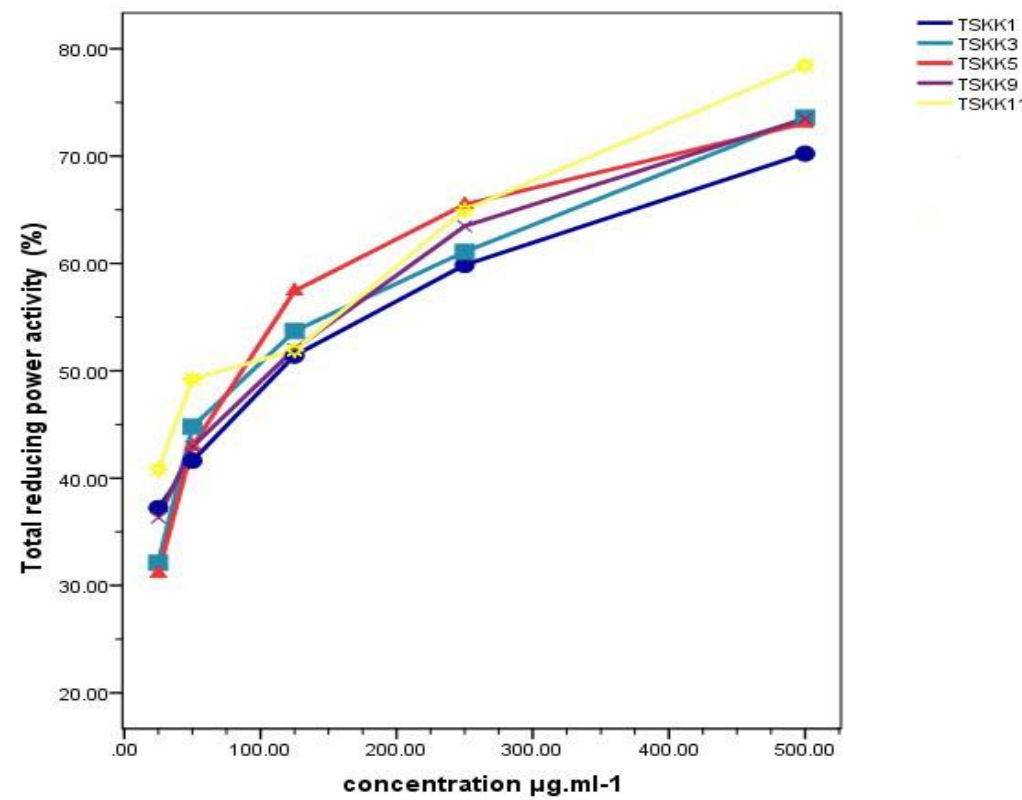

Fig. 6 - Total reducing power (\%) activity in extracts of mangrove-derived thraustochytrids, at different concentrations. 


\section{Discussion}

Marine thraustochytrids are becoming a potential source of polyunsaturated fatty acids (PUFA) (Gomathi 2011, Gomathi et al. 2013b). Docasahexaenoic acids and eicosapendaenoic acids are predominantly found in the marine thraustochytrids, which have recently attracted considerable research interest because of their diverse biological activities. The present study investigated the antioxidant activity of five marine thraustochytrids (TSKK1, TSKK3, TSKK5, TSKK9 and TSKK11) isolated from mangrove decaying leaf litter. The antioxidant properties were evaluated by using six different assays.

The potent strains of thraustochytrids species - TSKK1, TSKK3, TSKK5, TSKK9 and TSKK11 showed significat antioxidant activity with increasing concentrations of extracts (Figs 16). This is in accordance with previous antioxidant studies in bacteria, fungi, plants (Lu \& Foo 2000, Kim et al. 2002, Gomathi et al. 2013a, Saravanakumar \& Kathiresan 2014). Antioxidant activity has also been reported in Aplanochytrium sp., (KGA2512) (Gomathi et al. 2013a) and endophytic fungal extract of Trichoderma (EMFCAS8) (Saravanakumar \& Kathiresan 2014). The present study inferred that marine thraustochytrids were rich source of natural antioxidants (Table 1, Figs 1-6). In general, polyunsaturated fatty acid derivatives are reportedly responsible for such antioxidant activity in removal of toxic free radicals (Plaza et al. 2009). Omega-3 fatty acids are known for their important dietary roles as antioxidant and chemo-protective agents (Tlili et al. 2010). The omega-3 fatty acids are reportedly found commonly in plants, fungi, microalgae having several biological activities including antimicrobial, antioxidant, anti-apoptotic, anti-aging, anticarcinogenic properties (Huang \& Ebersole 2010, Guedes et al. 2011, Schmitz \& Ecker 2008, Mozaffarian \& Wu 2011).

Among different assays used, DPPH free radical scavenging assay is widely used as the most accurate screening method used to evaluate the antioxidant activity. The DPPH test provides information on the reactivity of test compounds with a stable free radical. DPPH is not affected by metals and enzyme inhibition. Because of its odd electron, 2, 2- diphenyl-picryl-hydrazyl radical (DPPH) gives a strong absorption band at $517 \mathrm{~nm}$ in visible spectroscopy (Brand-Williams 1995). The electron becomes paired off in the presence of a free radical scavenger, the absorption varnishes, thus the resulting decolourization is stoichiometric with respect to the number of electrons taken up. The scavenging properties of antioxidants are often associated with their ability to form stable radicals. The present study observed a considerable DPPH radical scavenging

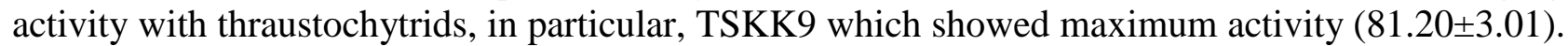
This can be attributed to the abundant presence of omega- 3 fatty acids in thraustochytrids as potential source for antioxidant and free-radical scavengers (Plaza et al. 2009, Gomathi et al. 2013a).

Natural polyphenols are important groups of metabolites which play a vital role in natural medicine in radical scavenging activity which increases with increasing concentration of polyphenols (Lu \& Foo 2000, Kim et al. 2002, Saravanakumar \& Kathiresan 2014). The reducing capacity of a compound may serve as an indicator of its potential antioxidant activity (Meir et al. 1995). The presence of reducing compounds causes reduction of the $\mathrm{Fe}^{3+} /$ ferricyanide complex to ferrous ion $\left(\mathrm{Fe}^{2+}\right.$. In the reducing power assay, reducing ability of a compound depends on the electron donor and free radical quenching capacity (Singh \& Rajini 2004). Reducing agents hinder lipid peroxidation as they donate a hydrogen atom and stop the chain reaction which causes membrane lipid damage (Xing 2005). There is a positive relationship between total phenol content and antioxidant activity (Lu \& Foo 2000).

Hydrogen peroxide is a normal cellular metabolite that is continuously generated and maintained at low concentrations. It is a weak oxidizing agent that inactivates a few enzymes directly, usually by oxidation of essential thiol (-SH) groups. It can cross cell membranes rapidly; once inside the cell, it can react with $\mathrm{Fe}^{2+}$ and possibly $\mathrm{Cu}^{2+}$ ions to form hydroxyl radicals and this may be the origin of many of its toxic effects (Miller et al. 1993). Hydrogen peroxide itself is not very reactive but sometimes it rapidly decomposes into oxygen and water producing hydroxyl 
radicals $\left(\mathrm{OH}^{-}\right)$that causes DNA damage (Halliwell 1991). The hydroxyl scavenging activity was found highly dependent on concentrations of the crude extracts of thraustochytrids (Table 1, Fig.4).

The total antioxidant capacity is used as an important screening tool for the identification of cancer risk patients and as a monitoring tool for the effect of drug treatments (Duan et al. 2006). Nitric oxide (NO) is a reactive free radical produced by phagocytes and endothelial cells, to yield more reactive species such as peroxy nitrite, which can be decomposed to form hydroxyl radical. The toxicity of NO increases greatly when it reacts with super oxide radical, forming the highly reactive peroxy nitrite anion (NOOO-) which leads to serious toxic reactions with biomolecules, such as protein, lipids and nucleic acids (Moncada et al. 1991). In the present study, the thraustochytrid extracts inhibited nitrite formation by directly competing with oxygen in the reaction with NO (Table 1, Fig.5).

This study proved that thraustochytrid species have potent free radical scavenging and antioxidant activity. The antioxidant mediated mechanism of thraustochytrids is hypothesized as a contributing factor for enhanced enzyme activity and reduced lipid peroxides as the antioxidant properties which can be correlated with oxidative stress defense in different human diseases. Antioxidants present in the diet can delay lipid peroxidation by inhibiting the initiation or propagation phase of oxidizing chain reactions by scavenging free radicals. The compounds present in the crude extracts may enhance the potency of the antioxidative property by additive or synergistic positive activity, while other compounds may neutralize or inhibit the antioxidation (Kulkarni 1997). In this regard, further purification of the crude extracts of thraustochytrids and evaluation of antioxidative activity is necessary to discover the antioxidant compounds present in the thraustochytrids. Thraustochytrid biomass and thraustochytrid-derived antioxidant compounds will have a very wide range of potential applications, from animal feed in aquaculture to human nutrition and health products.

\section{Acknowledgements}

The authors are grateful to the authorities of Annamalai University for providing facilities and to University Grants Commission (CPEPA-G4 (1)/1011/2012) and Ministry of Environment \& Forests, Government of India for financial assistance.

\section{References}

Badami S, Dongre SH, Suresh B. 2005 - In vitro antioxidant properties of Solanum pseudocapsicum leaf extracts. Indian Journal of Pharmacology 37(4), 251-252.

Brady SF, Bondi SM, Clardy J. 2001 - The guanacastepenes: a highly diverse family of secondary metabolites produced by an endophytic fungus. Journal of American Chemical Society 123, 9900-9901.

Brand-Williams W, Cuvelier ME, Berset C. 1995 - Use of a free radical method to evaluate antioxidant activity. LWT Food Science Technology 28, 25-30.

Cuzzocrea S, Riley DP, Caputi AP, Salvemini D. 2001 - Antioxidant therapy: a new pharmacological approach in shock, inflammation, and ischemia/reperfusion injury. Pharmacology Review 53(1), 135-59.

Duan XJ, Zhang WW, Li XM, Wang BG. 2006 - Evaluation of antioxidant property of extract and fractions obtained from a red alga, Polysiphonia urceolata. Food Chemistry 95(1), 3743.

Gomathi V. 2009 - Studies on thraustochytrids of mangrove sediments for poly unsaturated fatty acids and nanoparticles synthesis. M.Phil. Thesis, Annamalai University, India. pp. 63-65.

Gomathi V. 2011 - Studies on thraustochytrids isolated from mangrove biotope. Ph.D thesis, Annamalai University, India, 213 pp.

Gomathi V, Sithranga Boopathy N, Kayalvizhi K, Saravanakumar K, Kathiresan K. 2013a Antioxidant Properties of Mangrove-Derived thraustochytrids. Journal of Biotechnological Sciences 1(2), 108-112. 
Gomathi V, Saravanakumar K, Kathiresan K. 2013b - Production of polyunsaturated fatty acid (DHA) by mangrove-derived Aplanochytrium sp. African Journal of Microbiology Research Vol 7(13), 1098-1103.

Govindarajan R, Rastogi S, Vijayakumar M, Rawat AKS, Shirwaikar A, Mehrotra S, Pushpangadam P. 2003 - Studies on antioxidant activities of Desmodium gangetium. Biological Pharmaceutical Bulletin 26, 1424-1427.

Guedes AC, Amaro HM, Barbosa CR, Pereira RD, Malcata FX. 2011 - Fatty Acid Composition of Several Wild Microalgae and Cyanobacteria, with a focus on Eicosapentaenoic, Docosahexaenoic and Linolenic Acids for Eventual Dietary Uses. Food Research International 44, 2721-2729.

Gulcin I, Sat IG, Beydemi S, Kufrevioglu OI. 2004 - Evaluation of the in vitro antioxidant properties of Broccoli extracts (Brassica oleracea L.). Italian Journal of Food Science 16, $17-30$.

Gulcin I. 2011 - Antioxidant activity of eugenol: a structure-activity relationship study. Journal of Medicinal Food 14, 975-985.

Gulcin I. 2012 - Antioxidant activity of food constituents: an overview. Archives of Toxicology 86, $345-391$.

Halliwell B, Gutteridge JM, Aruoma OI. 1987 - The deoxyribose method: a simple 'test tube' assay for determination of rate contents for reaction of hydroxyl radicals. Analytical Biochemistry 165, 215-219.

Halliwell B.1991- Reactive oxygen species in living systems: Source, biochemistry, and role in human disease. American Journal of Medicine 91, 14-22.

Halliwell B.1995 - How to characterize an antioxidant: an update. Biochem Soc Symp 61, 73-101.

Huang CB, Ebersole JL. 2010 - A novel bioactivity of omega-3 polyunsaturated fatty acids and their ester derivatives. Journal of Molecular Oral Microbiology 25, 75-80.

Kathiresan K, Qasim SZ. 2005 - Biodiversity of Mangrove Ecosystems. Hindustan Publication Corporation, New Delhi, $251 \mathrm{pp}$.

Khansari N, Shakiba Y, Mahmoudi M. 2009 - Chronic Inflammation and Oxidative Stress as a Major Cause of Age-Related Diseases and Cancer Recent Patents on Inflammation \& Allergy Drug Discovery 3, 73-80.

Kim DO, Lee KW, Lee HJ, Lee CY. 2002 - Vitamin C equivalent antioxidant capacity (VCEAC of phenolic phytochemicals. Journal of Agriculture and Food Chemistry 50, 3713-3717.

Kim SK. 2013 - Marine Microbiology: Bioactive Compounds and Biotechnological Applications; Wiley VCH, Weinheim, Germany.

Kongsaeree P, Prabpai S, Sriubolmas N, Vongvein C, Wiyakrutta S. 2003 - Antimalarial Dihydroisocoumarins Produced by Geotrichum sp., an Endophytic fungus of Crassocephalum crepidioides. Journal of Natural Products 66, 709-711.

Kulkarni RD.1997 - Principles of Pharmacology in Ayurveda. Ram Sangam Graphics, Mumbai.

Lee J, Koo N, Min DB. 2004 - Reactive Oxygen Species, Aging and Antioxidative Nutraceuticals. Comprehensive Reviews in Food Science and Food Safety 3, 21-33.

Lee YS, Shin H, Han J, Lee M, Giacin JK. 2004 - Effectiveness of antioxidant-impregnated film in retarding lipid oxidation. Journal of Science and Food Agriculture 84, 993-1000.

Lu Y, Foo YL. 2000 - Antioxidant and free radical scavenging activities of selected medicinal herbs. Journal of Life Science 66, 725-735.

Meir S, Kanner J, Akiri B, Hadas SP. 1995 - Determination and involvement of aqueous reducing compounds in oxidative defense systems of various senescing leaves. Journal of Agriculture and Food Chemistry 43, 1813-1817.

Miller MJ, Sadowska-Krowicka H, Chotinaruemol S, Kakkis JL, Clark DA. 1993 - Amelioration of chronic ileitis by nitric oxide synthase inhibition. Journal of Pharmacology and Experimental theraphy 264, 11-16.

Moncada A, Palmer RM, Higgs EA. 1991- Nitric oxide: Physiology, pathophysiology and pharmacology. Pharmacology Review 43, 109-142. 
Mozaffarian D, Wu JH. 2011 - Omega-3 fatty acids and cardiovascular disease effects on risk factors, molecular pathways and clinical events. Americal Journal of Colloids 58, 20472067.

Oyaizu M.1986 - Studies on product of browning reaction prepared from glucose amine. Japan Journal of Nutrition 44, 307-315.

Plaza M, Herrero M, Cifuentes A, Ibanez E. 2009 - Innovative natural functional ingredients from microalgae. Journal of Agriculture and Food Chemistry 57, 7159 -7170.

Prieto P, Pineda M, Aguilar M. 1999 - Spectrophotometric quantitation of antioxidant capacity through the formation of a phosphomolybdenum complex: specific application to the determination of vitamin E. Annals of Biochemistry 269, 337-341.

Saravanakumar K, Kathiresan K. 2014 - Antioxidant activity of the mangrove endophytic fungus (Trichoderma sp.), Journal of Coastal Life Medicine 2(7), 566-570

Schmitz G, Ecker J. 2008 - The opposing effects of n-3 and n-6 fatty acids. Progress in Lipid Research 47, 147-155.

Shrestha K, Strobel GA, Shrivastava SP, Gewali MB. 2001 - Evidence for paclitaxel from three new endophytic fungi of Himalayan yew of Nepal. Planta Medica 67, 374-376.

Singh N, Rajini PS. 2004 - Free radical scavenging activity of an aqueous extract of potato peel. Food Chemistry 85, 611-616.

Singleton VL, Orthofer R, Lamuela RM. 1999 - Analysis of total phenols and other oxidation substrates and antioxidant by means of Folin-Ciocalteu reagent. Methods in Enzymology 299, 152-178.

Song FL, Gan RY, Zhang Y, Xiao Q, Kuang L, Li HB. 2010 - Total phenolic contents and antioxidant capacities of selected Chinese medicinal plants. International Journal of Molecular Sciences 11(6), 2362 - 2372.

Sridhar KR. 2004 - Mangrove fungi in India. Current Science 86, 1586-1587.

Tlili N, Khaldi A, Triki S, Munne BS. 2010 - Phenolic Compounds and Vitamin Antioxidants of Caper (Capparis spinosa). Plant Foods Human Nutrition 65, 260-265.

Wagenaar MM, Clardy J. 2001 - Dicerandrols, new antibiotic and cytotoxic dimers produced by the fungus Phomopsis longicolla isolated from an endangered mint. Journal of Natural Products 64, 1006-1009.

Xing R, Yu H, Liu S, Zhang W. 2005 - Antioxidant activity of differently region selective chitosan sulfates in vitro. Bio organic and Medicinal Chemistry 13, 1387-1392. 